140

The Open
Orthopadics
lournal

RESEARCH ARTICLE

\title{
Analysis of the Influence of Osteosynthesis Technique and Patient-specific Factors on the Outcome of Subtrochanteric Fracture Treatment
}

\author{
Christoph Schulze ${ }^{1,2, *}$, Erwin Kollig ${ }^{3}$, Katharina Estel ${ }^{4}$, Claudia Hacke ${ }^{5}$, Andre Gutcke ${ }^{2}$ and Dan Bieler ${ }^{3}$ \\ ${ }^{1}$ Department of Orthopaedics, University Medicine Rostock, Doberaner Str. 142, D-18057 Rostock, Germany \\ ${ }^{2}$ Department of Trauma Surgery, Armed Forces Hospital Westerstede, Lange Str. 38, 26655 Westerstede, Germany \\ ${ }^{3}$ Department of Trauma Surgery and Orthopaedics, Reconstructive Surgery, Hand Surgery and Burn Medicine, Bundeswehr Central Hospital \\ Koblenz, Ruebenacher Str. 170, 56072 Koblenz, Germany \\ ${ }^{4}$ Department of Trauma Surgery, Bundeswehr Hospital Berlin, Scharnhorststr. 13, 10115 Berlin, Germany \\ ${ }^{5}$ Department of Paediatrics I, Universitätsklinikum Schleswig-Holstein, Campus Kiel, Arnold-Heller-Straße 3, 24105 Kiel, Germany
}

\begin{abstract}
:
Objective:

The number of subtrochanteric femoral fractures will continue to grow on account of demographic developments. The treatment of choice is reduction and surgical stabilisation. Intramedullary (IO) and extramedullary (EO) techniques are available for this purpose. A final assessment has not been made of which technique is superior with regard to treatment outcome, complication rates, and revision rates. The objective of this retrospective study was to compare surgical procedures with regard to weight bearing, length of hospital stay, the occurrence of complications, and the necessity of surgical revisions.

\section{Methods:}

This retrospective study included 77 patients ( $74.9 \pm 14.9$ years; $42.9 \%$ male). Associations between surgical procedures and treatment outcomes, complications and revision rates were calculated by linear and logistic regression analysis. To investigate the effect of surgical procedure within patients with fracture type $2 \mathrm{~B}$ according to Russel-Taylor classification, a subgroup analysis was performed.

Results:

In case of fracture type $2 \mathrm{~B}$, according to Russell-Taylor classification, EO took 80 minutes longer on average than the intramedullary technique (p $=0.001$ ), although surgeon experience plays an important role. Common complications were more frequently associated with IO than with EO. Surgical revisions were required more often in the extramedullary group (OR 4.5; 95\% CI: $0.87-23.19$ ). Patients in the intramedullary group were discharged 3.4 days earlier from the hospital $(\mathrm{p}=0.024)$. Older patients had a higher risk for the occurrence of complications, but BMI and the experience of the surgeon did not. Patients with intramedullary stabilisation frequently showed better postoperative weight-bearing stability.

\section{Conclusion:}

The intramedullary technique offers advantages to both patients and hospitals with regard to outcome, duration of surgery, and length of stay in the hospital. Although, extramedullary implants are less expensive, this advantage is clearly reduced by the longer duration of surgery and hospital stays.
\end{abstract}

Keywords: Subtrochanteric femoral fracture, Extramedullary intramedullary fixation, Duration surgery, Complications, Length hospital stay, fracture type $2 \mathrm{~B}$.

\begin{tabular}{|l|l|l|l}
\hline Article History & Received: June 23, 2020 & Revised: September 04, 2020 & Accepted: September 11, 2020
\end{tabular}

\section{INTRODUCTION}

Subtrochanteric femoral fractures are increasing in number and thus becoming more and more relevant for trauma sur-

Address correspondence to this author at Department of Orthopaedics University Medicine Rostock Doberaner Str. 14218057 Rostock, Germany; Tel: +49(0)381 4949335; Fax: +490381 4949308;

E-mail: christoph.schulze@med.uni-rostock.de geons [1]. They account for 8 to $15 \%$ of all proximal femoral fractures $[2,3]$. The mortality rate of patients with this type of fracture is between 5 and $15 \%[4,5]$. Studies show, however, a clear difference between the mortality rate in hospitals (4 to $6 \%$ ) and one-year mortality (up to $30 \%$ ) [3, 6]. The subtrochanteric region refers to the area between the lesser trochanter and a point $5 \mathrm{~cm}$ distal [7]. If trauma occurs, this region is subject to a level of mechanical stress that is 
unmatched in other regions of the human body [8]. This leads to a thick cortical layer, and fractures are often comminuted [8]. In addition, fractures in this region are comparatively slow region is relatively wide, which makes it more difficult to stably fixate an intramedullary nail than further distal [7]. Another problem is that many strong muscles are attached to the proximal femur around the hip joint. As a result, typical signs of a fracture are external rotation, shortening, and adduction of the affected leg [2, 10]. This is why subtrochanteric fractures pose biomechanical challenges to every kind of implant. The various muscles around the proximal femur pull in opposite directions in the subtrochanteric region, which promotes pseudoarthrosis [11]. In the literature, pseudoarthrosis rates range from 2 to $20 \%$ depending on reduction and cerclage wire use $[12,13]$.

Various classification methods for subtrochanteric fractures are described in the literature, but only a few, however, have proved to be useful for determining surgical technique or for predicting surgical outcomes [14]. The following classifications are currently well established: the Seinsheimer classification [15], the AO (Arbeitsgemeinschaft für Osteosynthesefragen; AO-Foundation) classification [16], and the Russell-Taylor classification [17]. The latter can be used to make decisions about surgical technique [7,9]. No classification was able to predict the outcome of treatment $[18$, 19]. In the majority of cases, surgical treatment of the fracture performed in selected cases [2]. The objective of surgery is to reconstruct the length and the anatomical alignment of the limbs concerned [20]. The chosen treatment method should facilitate early mobilisation, particularly for elderly patients [20]. Either intramedullary implants are used, which are inserted in a minimally invasive approach after closed reduction, or an open procedure is performed with plate fixation after successful reduction [21]. The duration of surgery varies considerably depending on the technique used $[4,22]$. Experienced surgeons can implant intramedullary devices much faster than extramedullary devices [4, 20]. Femoral nails are especially suitable for the treatment of fractures because they can be inserted in a minimally invasive approach. They also help restore biomechanical stability, and they accelerate postoperative mobilisation $[4,7,11]$. These advantages are important especially for complex fractures involving the trochanter region [7]. Extramedullary devices include the 95degree angled blade plate, the 95-degree dynamic condylar to heal $[8,9]$. The medullary cavity in the intertrochanteric is the primary treatment option. Conservative treatment is only

screw (DCS), the dynamic hip screw (DHS), and systems providing angular stability such as the locking compression plate (LCP) [11]. The frequency in the use of these devices varies greatly. Further advantages of these plates are that it is not necessary to create a bone defect in order to achieve the optimal bone position and that good fixation of the proximal fragment can be ensured [7]. Unfavourable mechanical properties and difficult positioning by the surgeon after the reduction, however, limit the number of cases in which plates can be used [11]. In clinical settings, plates are used for revision surgery and to treat pseudoarthrosis [11].

In the literature, frequency and clinical application vary considerably on account of different postoperative results [23 25]. Similar to the 95-degree angled blade plate/condylar plate, revision surgery outcomes are reported to be satisfactory [26]. Although complication rates have decreased in recent years due to constant improvements in technique and the materials used, adverse events occur in up to a quarter of patients [27]. The aim of this study was to find out whether intramedullary or extramedullary systems have advantages in terms of outcome (mobilisation, complications) and cost-effectiveness (duration of surgery and hospital stay).

\section{MATERIALS AND METHODS}

\subsection{Patients}

Suitable patient data were retrospectively collected from the information systems of the two participating hospitals. Patients with diagnosed subtrochanteric fractures from 2006 to 2015 were imbedded in this study. This was done by searching for patients with a diagnosis of subtrochanteric femoral fracture in the digital clinic information system (ORBIS $^{\mathrm{TM}}$, AGFA Healthcare, Bonn, Germany). The patients' X-rays were evaluated and the diagnoses were verified. Table 1 shows the distribution of severity according to the Russell-Taylor classification. For our retrospective study, we identified 77 patients (aged $74.9 \pm 14.9$ years; $42.9 \%$ male) who were diagnosed with subtrochanteric femoral fractures between 2008 and 2016. Relevant data (height, weight, age at the time of the surgery, type of surgery) were extracted from the data sets, anonymised, and analysed. The target parameters in this study were incision-to-closure time, postoperative weight bearing, length of hospital stay, the occurrence of complications, and the necessity of surgical revision. Table $\mathbf{2}$ shows the basic data of the selected study group.

Table 1. The Russell-Taylor classification considers involvement of the lesser trochanter and the piriformis fossa and may thus influence decisions on surgical technique. $N$ is the number of cases considered in this study.

\begin{tabular}{|c|c|c|}
\hline Classification & Type I & Type II \\
\hline & $\begin{array}{c}\text { piriformis fossa / } \\
\text { trochanter intact }\end{array}$ & $\begin{array}{c}\text { piriformis fossa / } \\
\text { trochanter not intact }\end{array}$ \\
\hline & $\begin{array}{c}\text { A: } \\
\text { lesser trochanter attached to proximal fragment } \\
(\mathrm{N}=8)\end{array}$ & Stable posterior-medial buttress \\
& \begin{tabular}{c}
$\mathrm{N}=1)$ \\
\hline
\end{tabular}
\end{tabular}


(Table 1) contd.....

\begin{tabular}{|c|c|c|}
\hline Classification & Type I & Type II \\
\hline & B: & B: \\
& lesser trochanter detached from proximal fragment & posterior-medial buttress not intact - comminution of piriformis fossa / lesser \\
& $(\mathrm{N}=27)$ & trochanter \\
\end{tabular}

Table 2. Characteristics of the study population.

\begin{tabular}{|c|c|c|c|}
\hline Technique & Age, years ( \pm SD) & Weight, kg ( \pm SD) & BMI, kg/m $\mathbf{~}^{\mathbf{(} \pm \text { SD) }}$ \\
\hline Nail osteosynthesis $(\mathrm{N}=64)$ & $76.2( \pm 12.8)$ & $75.1( \pm 12.7)$ & $26.2( \pm 4.2)$ \\
\hline Plate osteosynthesis $(\mathrm{N}=13)$ & $68.6( \pm 22.0)$ & $74.4( \pm .14 .0)$ & $24.9( \pm 4.0)$ \\
\hline p value & 0.094 & 0.858 & 0.344 \\
\hline
\end{tabular}

\subsection{Surgical Techniques}

Intramedullary technique: After fracture reduction on the fracture table, an $8 \mathrm{~cm}$ long skin incision is made proximal to the greater trochanter and the iliotibial tract is split. A guide wire is inserted with an aiming device, the proximal femur is drilled, and a suitable intramedullary nail is introduced (Gamma3 trochanteric nail, Gamma3 long nail, both produced by Stryker $\mathrm{GmbH} \& \mathrm{Co}$. KG, Kiel, Germany). Image intensification is used to confirm that the nail is well positioned in both planes. A hip screw and a distal locking screw are inserted through a stab incision using the aiming device and fluoroscopic guidance. If necessary, a drain is inserted, followed by wound closure. An example of the intramedullary technique in case of subtrochanteric fracture (Russel-Taylor Type 2 B) is shown in Fig. (1).

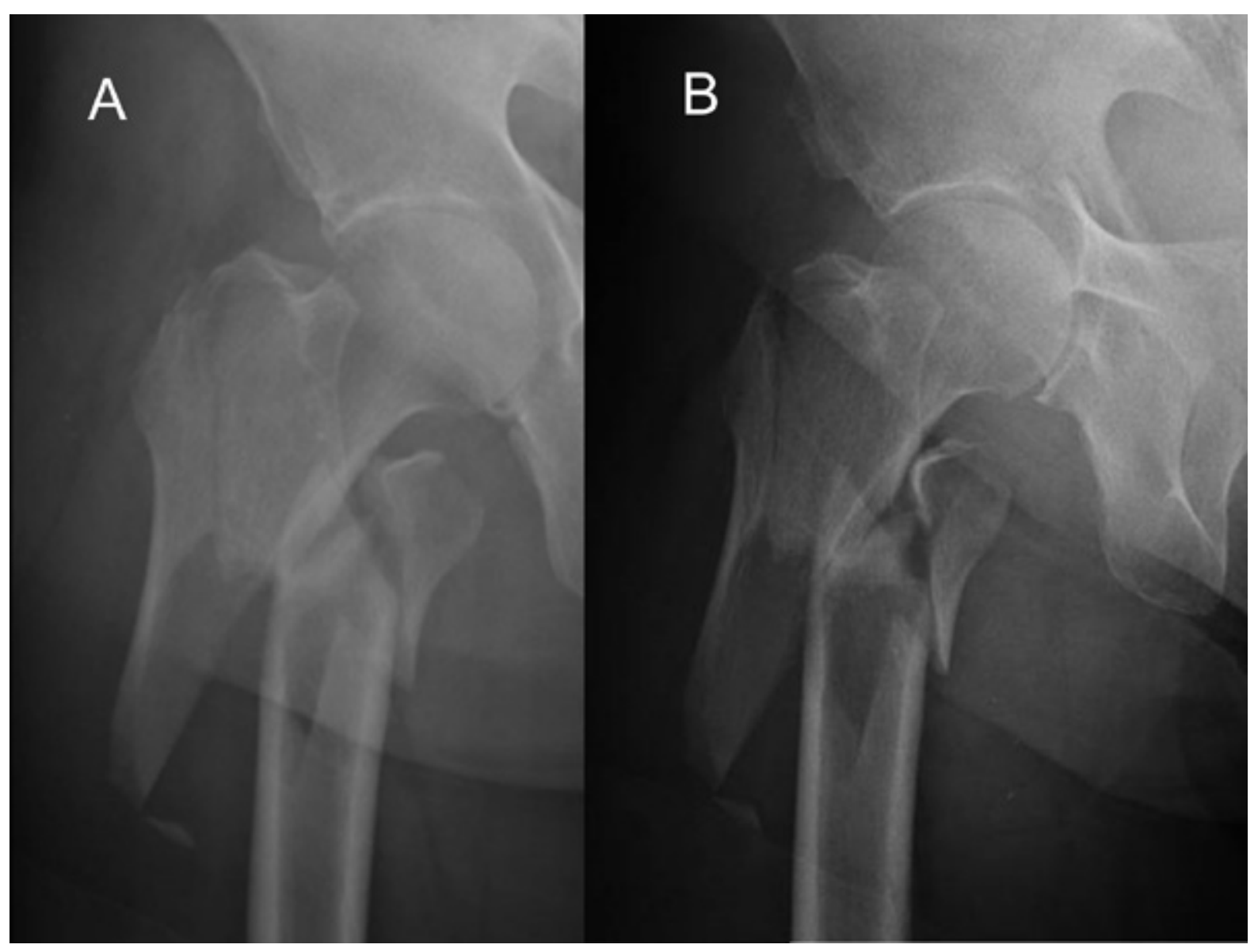

Fig. 1 contd..... 


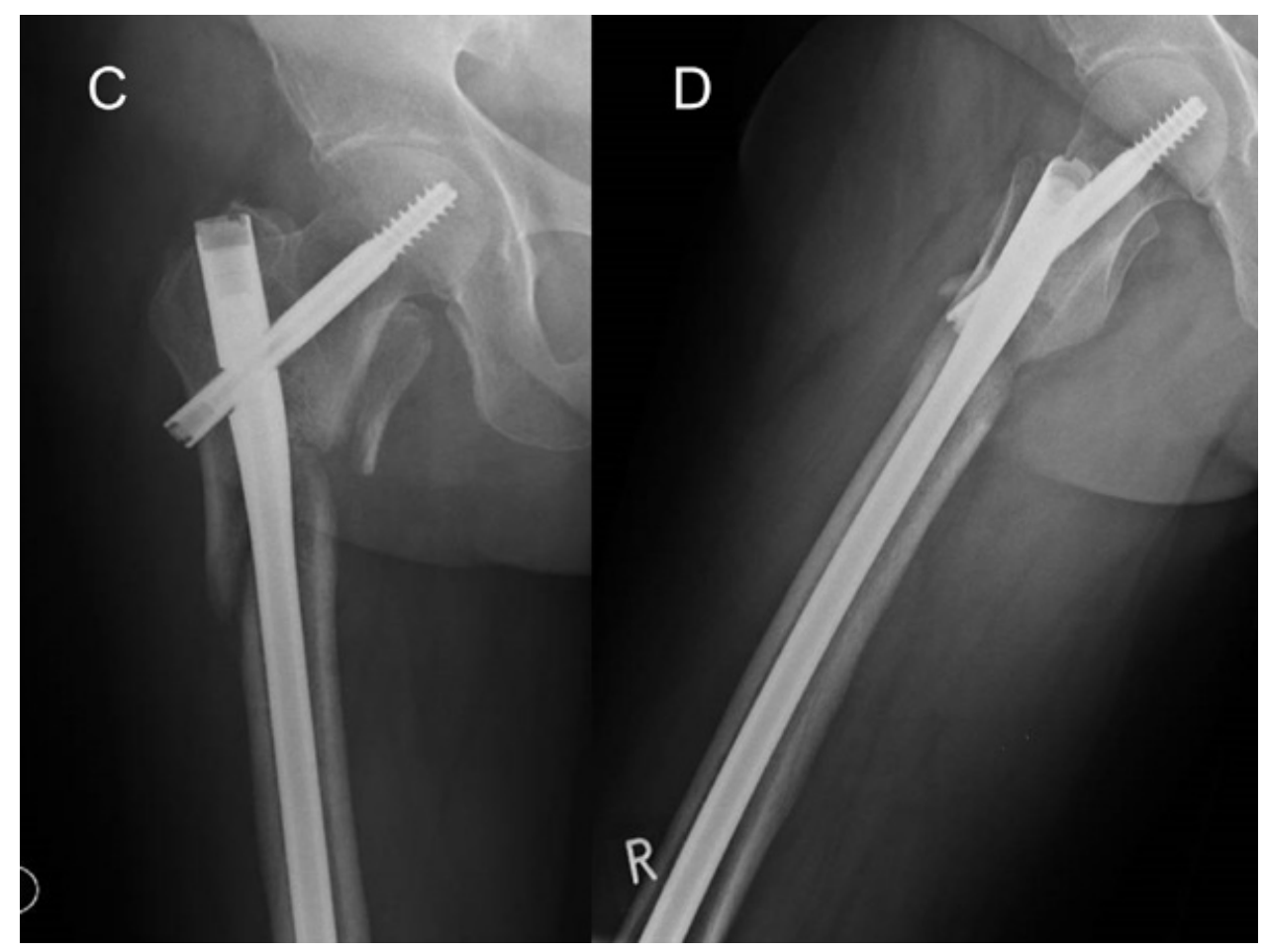

Fig. (1). Typical case of subtrochanteric fracture type 2B (Russel-Taylor). Intramedullary Fixation with Gamma3 long nail (Stryker GmbH \& Co. KG, Kiel, Germany).

A: anterior-posterior view preoperative. B: second plane preoperative. C: anterior-posterior view postoperative. D: second plane postoperative.

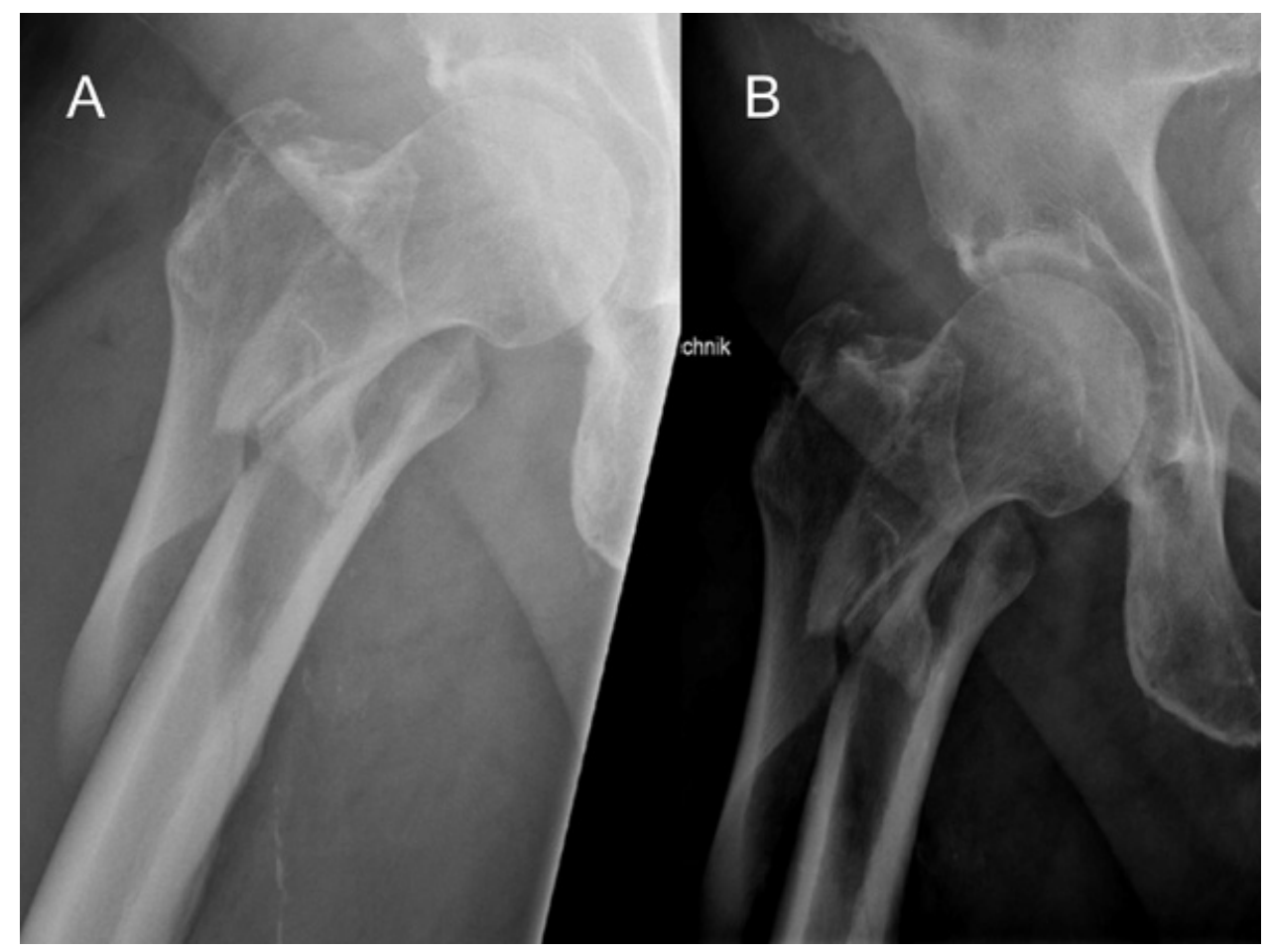

Fig. 2 contd..... 

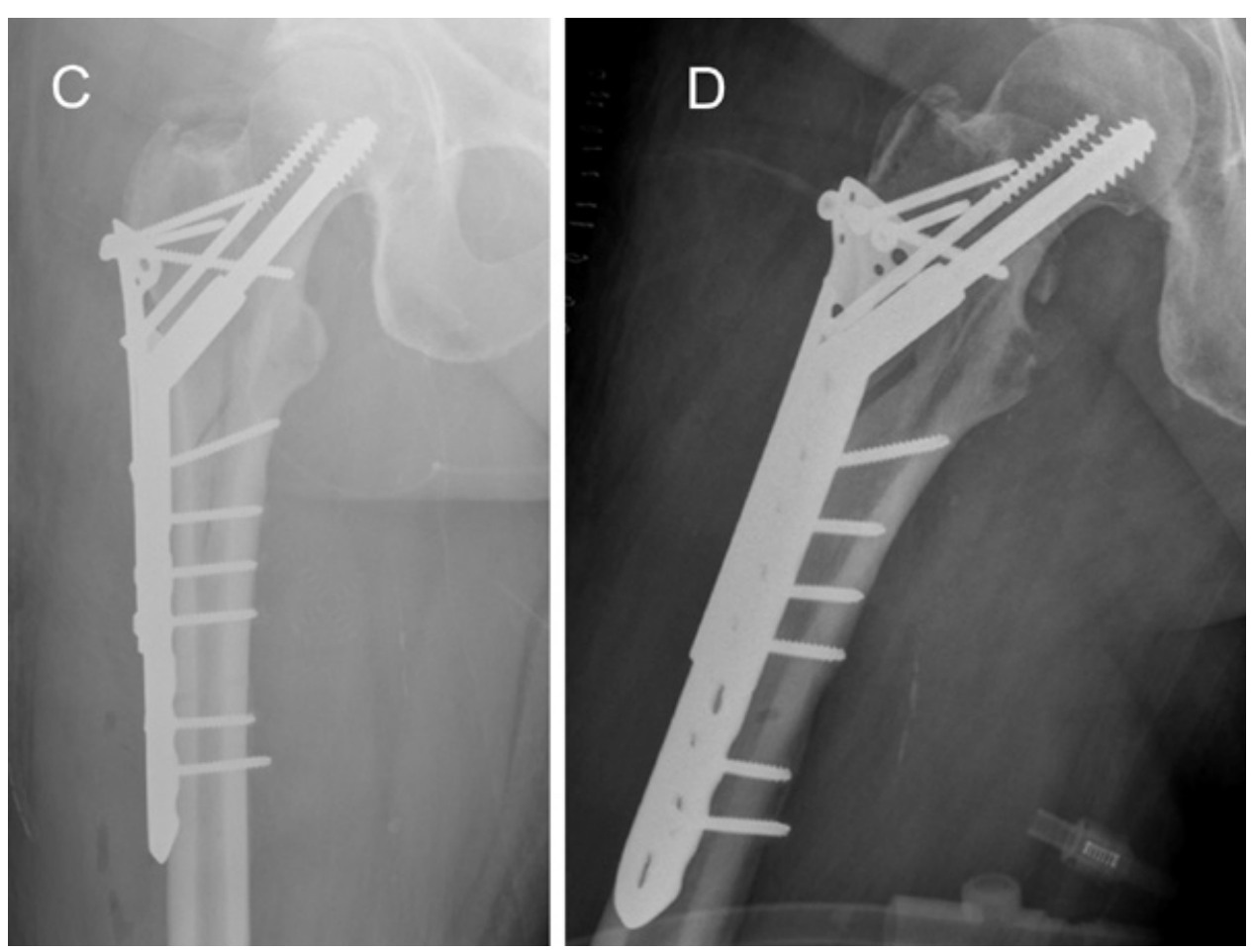

Fig. (2). Typical case of subtrochanteric fracture type 2B (Russel-Taylor). Extramedullary Fixation with DCS and LCDC titanium plate (DePuy Synthes, Umkirch, Germany).

A: anterior-posterior view preoperative. B: second plane preoperative. C: anterior-posterior view postoperative. D: second plane postoperative.

Extramedullary technique: It is used for complex subtrochanteric fractures. A ventral antirotation plate is used to fulfil the special biomechanical requirements of the subtrochanteric region and to counteract the pull of the attached muscles.

Surgery is conducted with the patient positioned supine on a fracture table. Following lateral access to the left proximal femur, an L-shaped incision is made in the vastus lateralis at the greater trochanter. The proximal femur and the fracture region are exposed without retracting the periosteum. If required, the fracture line between the greater trochanter and the neck fragment is closed. The fracture is then reduced. The next step is to introduce the guide wire for the DCS (Dynamic Compression Screw) load-bearing screw (titanium DCS, produced by DePuy Synthes, Umkirch, Germany) using an aiming device under fluoroscopic guidance. Measuring, drilling and thread cutting are followed by the insertion of a loadbearing screw. The plate is then definitively repositioned. After the position of the plate is checked, the holes are predrilled and the depth of the holes is measured. Bicortical screws are then inserted. Ideally, fragments at the lesser trochanter are repositioned in the dorsomedial direction and fixed with screws. With regard to the subtrochanteric morphology of the fracture and in anticipation of the special biomechanical properties, a narrow LCDC (Limited Contact Dynamic compression) titanium plate (DePuy Synthes, Umkirch, Germany) is attached ventrally at a 90-degree angle to the DCS under fluoroscopic guidance. A deep Redon drain is inserted to determine whether bleeding has stopped. The vastus lateralis is reattached to the trochanter by a pulley suture. This is followed by wound closure. An example of the extramedullary technique in case of subtrochanteric fracture (Russell-Taylor Type 2 B) is shown in Fig. (2).

\subsection{Surgeons Experience}

The experience of the conducting surgeon was classified as a specialist or assistant. Specialist means more than 6 years of experience in surgery whereas assistant means less than 6 years of surgical experience.

\subsection{Statistical Evaluation}

Descriptive analyses of continuous variables were reported as means \pm 1 standard deviation (SD), $95 \%$ confidence interval (CI). Absolute and relative frequency distributions were used for categorical data. The normal distribution of the data was tested by the Shapiro-Wilk test and, as a graphical method, a Q-Q plot. We analysed the influence of the surgical technique on the duration of surgery and the length of hospital stay as dependent variables by means of simple and multiple linear regression, also taking surgeon (Model 1), age and BMI into account (Model 2). To show more comparable influences, a regression analysis among patients with fracture type $2 \mathrm{~B}$ only was performed (EO: $\mathrm{N}=21$; IO $\mathrm{N}=20$ ). The unstandardised regression coefficient (b) \pm standard error (SE) and a CI of $95 \%$ were given as an effect estimator. Adjusted $R^{2}$ was used as a measure of the goodness of fit of the regression model. The probability of complications and of revision surgery was calculated in logistic regression models with an odds ratio (OR) and $95 \%$ CI. The chi-squared test was used to find differences in postoperative weight bearing between the two 
surgical techniques. The significance level was set at $\alpha=5 \%$ (p $<0.05$ ). All data were analysed using IBM SPSS Statistics 23.0 (SPSS, Chicago, IL).

\section{RESULTS}

\subsection{Duration of Surgery}

Including all cases and fracture types, extramedullary osteosynthesis (EO) took longer than intramedullary osteosynthesis (IO, Table 3). To show more comparable influences, a simple regression analysis including only fracture type $2 \mathrm{~B}$ was performed (EO: $\mathrm{N}=21$; IO $\mathrm{N}=20$ ). In the cases of type 2 B fractures EO took 80 minutes longer than IO (b: 80.0 ; standard error [SE]: 16.7 ; 95\%-Confidence Interval (95\%-CI): $46.5 ; 113.5 ; \mathrm{p}<0.001$ ). Two variables (surgical technique and the surgeon's experience) explained $17 \%$ of the variance in the duration of surgery $(p<0.001)$. The surgical technique is, however, more important than the surgeon's experience (Table 4). Body-Mass-Index (BMI) and age did not have a statistically significant influence on the duration of surgery (data not shown) in our study group $(\mathrm{n}=54)$.

\subsection{Length of Hospital Stay}

The general comparison between the two osteosynthesis techniques showed that EO involved significantly longer stays in the hospital than IO (Table 3). The results of the simple regression analysis, in particular for type $2 \mathrm{~B}$ fractures, indicate that the osteosynthesis technique has a significant influence on the length of hospital stay. EO was associated with a 5-day increase in the average length of stay (b: 4.9; SE: 1,7 95\%-CI $1.3 ; 8.4 ; \mathrm{p}=0.008)$.

Age proved to be a significant predictor in the multiple regression model ( $\mathrm{B}=0.2 ; 95 \% \mathrm{CI}:-0.3 ;-0.1, \mathrm{p}=0.002)$. However, the length of hospital stay increased by 3 days after EO, which was clinically relevant but not statistically significant $(\mathrm{p}<0.09)$ (Table 5). The length of stay, however, changes significantly by 0.19 days per year; as age increases, stays shorten (Table 4). This is used in a regression equation that estimates the length of hospital stay on the basis of fracture, fracture treatment, and patient age: length of stay (in days) $=24.561+3.012 \times$ technique $+-0.188 \times$ age .

If age and BMI are considered in addition to surgical technique and the surgeon's experience, $21.1 \%$ of the variance can be explained; age was the strongest predictor (standardised regression coefficient beta $=0.418$ ) and BMI the weakest predictor (standardised regression coefficient beta $=0.083$ ). This model is significant only in terms of age $(p=0.002)$. The predictors BMI, the surgeon's experience, and the surgical technique are not significant (Table 5).

Table 3. Descriptive statistics of the group with a comparison of important criteria for the outcome of the two techniques (SD= standard deviation).

\begin{tabular}{|c|c|c|c|c|}
\hline Technique & Duration of surgery in minutes $( \pm \mathbf{S D})$ & Length of hospital stay, days $( \pm$ SD) & $\begin{array}{c}\text { Complications, } \\
\mathbf{N}(\%)\end{array}$ & $\begin{array}{c}\text { Revision surgery, } \\
\mathbf{N}(\%)\end{array}$ \\
\hline $\begin{array}{c}\text { Intramedullary osteosynthesis } \\
(\mathrm{N}=64)\end{array}$ & $91( \pm 63)$ & $13.3( \pm 6.3)$ & $27(42 \%)$ & $4(6.3 \%)$ \\
\hline $\begin{array}{c}\text { Extramedullary osteosynthesis } \\
(\mathrm{N}=13)\end{array}$ & $157( \pm 46)$ & $17.7( \pm 6.8)$ & $3(23 \%)$ & $3(23.1 \%)$ \\
\hline
\end{tabular}

Table 4. Results of multiple linear regression with respect to the duration of surgery. Model 1: regression analysis adjusted for surgeon. Model 2: regression analysis adjusted for surgeon, age and BMI.

\begin{tabular}{|c|c|c|c|c|c|c|c|c|c|}
\hline \multicolumn{10}{|c|}{ Duration of surgery } \\
\hline Model 1 & b (SE) & $95 \% \mathrm{CI}$ & beta & p value & Model 2 & b (SE) & $95 \%$ CI & beta & p value \\
\hline Technique (IO vs. EO) & 53.4 (19.4) & $15.5-91.4$ & 0.309 & 0.006 & Technique (IO vs. EO) & $39.8(24.0)$ & $-8.3 ; 88.0$ & 0.224 & 0.103 \\
\hline \multirow[t]{3}{*}{$\begin{array}{c}\text { Surgeon (assistant vs } \\
\text { specialist) }\end{array}$} & $31.5(15.1)$ & $1.4-61.6$ & 0.23 & 0.04 & Surgeon (assistant $v s$ specialist) & $26.6(21.9)$ & $-17.4 ; 70.5$ & 0.165 & 0.231 \\
\hline & & & & & Age & $-0.9(0.6)$ & $-2.1 ; 0.2$ & -0.218 & 0.105 \\
\hline & & & & & BMI & $3.2(2.2)$ & $-1.1 ; 7.6$ & 0.195 & 0.139 \\
\hline
\end{tabular}

$\mathrm{b}=$ unstandardised regression coefficient, $\mathrm{SE}=$ standard error, $95 \% \mathrm{CI}=95 \%$ confidence interval, beta $=$ standardised regression coefficient, IO $=$ intramedullary osteosynthesis, $\mathrm{EO}=$ extramedullary osteosynthesis, $\mathrm{BMI}=$ Body-Mass-Index.

Table 5. Results of multiple linear regression with respect to the length of hospital stay. Model 1: regression analysis adjusted for surgeon. Model 2: regression analysis adjusted for surgeon, age and BMI.

\begin{tabular}{|c|c|c|c|c|c|c|c|c|c|}
\hline \multicolumn{10}{|c|}{ Length of hospital stay } \\
\hline Model 1 & b (SE) & $\mathbf{9 5 \%}$ CI & Beta & p value & Model 2 & b (SE) & 95\% CI & beta & p value \\
\hline $\begin{array}{c}\text { Technique } \\
\text { (IO } v \text { s. EO) }\end{array}$ & $3.1(2.0)$ & $-0.9 ; 7.0$ & 0.182 & 0.124 & $\begin{array}{c}\text { Technique } \\
\text { (IO } v s \text {. EO) }\end{array}$ & $3.0(2.5)$ & $-2.0 ; 7.9$ & 0.160 & 0.235 \\
\hline Surgeon (assistant $v$ specialist) & $3.3(1.6)$ & $0.2 ; 6.5$ & 0.246 & 0.038 & Surgeon (assistant $v s$ specialist) & $2.1(2.3)$ & $-2.6 ; 6.7$ & 0.118 & 0.374 \\
\hline & & & & & Age & $-0.2(0.6)$ & $-0.3 ;-0.1$ & -0.418 & 0.002 \\
\hline
\end{tabular}


(Table 5) contd.....

\begin{tabular}{|c|c|c|c|c|c|c|c|c|c|}
\hline \multicolumn{10}{|c|}{ Length of hospital stay } \\
\hline Model 1 & b (SE) & $95 \% \mathrm{CI}$ & Beta & p value & Model 2 & b (SE) & $95 \% \mathrm{CI}$ & beta & p value \\
\hline & & & & & BMI & $0.2(0.2)$ & $-0.3 ; 0.6$ & 0.083 & 0.514 \\
\hline
\end{tabular}

osteosynthesis, EO = extramedullary osteosynthesis, BMI = Body-Mass-Index

\subsection{Complications/revision Surgery}

A comparison between the two surgical techniques showed that IO involved more common complications in the study group considered (Table 3). Simple regression analysis for the $2 \mathrm{~B}$ fracture type cohort showed no significant differences in the occurrence of complications between IO and EO (OR: 1.4; $95 \%$-CI $0.2 ; 9.3 ; \mathrm{p}=0.663$ ). However, increasing age led to a significant increase of complications in case of patients with type 2 B fractures and EO (OR: $0.9 ; 95 \%-C I$ : $0.76 ; 0.96$; $\mathrm{p}=0.007$ ). The percentage of complications that required surgical revision was, however, higher with EO (Table 3). These findings are supported by the results of the logistic regression $(\mathrm{OR}=2.424 ; 95-\mathrm{CI}: 0.6 ; 10.3 ; \mathrm{p}=0.229$; Table 6) but have no statistical significance. The results change negligibly when age is considered (Table 6). In addition, the influence of BMI could not be found in the group.

In general, the probability of necessary surgical revisions was 4.5 times higher after EO than after IO (OR 3.5; 95\%-CI: 0.6 ; -20.1). This clinically relevant difference was not statistically significant either, but a trend is obvious $(p=0.16)$. When age is also taken into consideration, the risk becomes more moderate and the probability of surgical revision is only 3.2 times higher (Table 7). The result is not significant. All observed complications are listed up in Table 8.

Table 6. Results of binary logistic regression with respect to the occurrence of complications. Model 1: regression analysis adjusted for surgeon. Model 2: regression analysis adjusted for surgeon, age and BMI.

\begin{tabular}{|c|c|c|c|c|c|c|c|c|c|}
\hline \multicolumn{10}{|c|}{ Occurrence of complications } \\
\hline Model 1 & b (SE) & OR & $95 \%$ CI & $p$ value & Model 2 & b (SE) & OR & $95 \%$ CI & p value \\
\hline $\begin{array}{l}\text { Technique } \\
\text { (IO vs. EO) }\end{array}$ & $0.89(0.74)$ & 2.424 & $0.6 ; 10.3$ & 0.229 & $\begin{array}{l}\text { Technique } \\
\text { (IO vs. EO) }\end{array}$ & $0.6(0.8)$ & 1.827 & $0.4 ; 8.7$ & 0.450 \\
\hline \multirow[t]{3}{*}{ Surgeon (assistant $v s$ specialist) } & $0.01(0.52)$ & 1.008 & $0.4 ; 2.8$ & 0.987 & Surgeon (assistant $v s$ specialist) & $0.3(0.7)$ & 1.304 & $0.3 ; 5.0$ & 0.698 \\
\hline & & & & & Age & $-0.01(0.02)$ & 0.990 & $0.95 ; 1.03$ & 0.578 \\
\hline & & & & & BMI & $0.01(0.07)$ & 1.006 & $0.9 ; 1.2$ & 0.934 \\
\hline
\end{tabular}

$\mathrm{b}=$ unstandardised regression coefficient, $\mathrm{SE}=$ standard error, $95 \% \mathrm{CI}=95 \%$ confidence interval, $\mathrm{OR}=$ odds ratio, IO $=$ intramedullary osteosynthesis, EO $=$ extramedullary osteosynthesis, BMI = Body-Mass-Index.

Table 7. Results of binary logistic regression with respect to the frequency of revision surgery. Model 1: regression analysis adjusted for surgeon. Model 2: regression analysis adjusted for surgeon, age and BMI.

\begin{tabular}{|c|c|c|c|c|c|c|c|c|c|}
\hline \multicolumn{10}{|c|}{ Occurrence of complications } \\
\hline Model 1 & b (SE) & OR & $95 \% \mathrm{CI}$ & p value & Model 2 & b (SE) & OR & $95 \%$ CI & p value \\
\hline Technique (IO vs. EO) & $1.3(0.9)$ & 3.500 & $0.6 ; 20.1$ & 0.16 & Technique (IO vs. EO) & $1.2(1.0)$ & 3.193 & $0.4 ; 8.7$ & 0.243 \\
\hline \multirow[t]{3}{*}{$\begin{array}{c}\text { Surgeon (assistant vs } \\
\text { specialist) }\end{array}$} & $0.8(1.2)$ & 2.143 & $0.2 ; 21.8$ & 0.52 & Surgeon (assistant $v s$ specialist) & $18.6(11084.7)$ & 119941023.3 & 0.000 & 0.999 \\
\hline & & & & & Age & $-0.04(0.02)$ & 0.964 & $0.92 ; 1.01$ & 0.134 \\
\hline & & & & & BMI & $-0.01(0.13)$ & 0.997 & $0.78 ; 1.28$ & 0.978 \\
\hline
\end{tabular}

$\mathrm{b}=$ unstandardised regression coefficient, $\mathrm{SE}=$ standard error, $95 \% \mathrm{CI}=95 \%$ confidence interval, OR $=$ odds ratio, IO $=$ intramedullary osteosynthesis, EO $=$ extramedullary osteosynthesis, BMI = Body-Mass-Index.

Table 8. Number of complications in the observed population with regard to operative procedure and severity of the fracture classified according to Russel-Taylor. More than one complication per case is possible. (IO=intramedullary osteosynthesis, EO=extramedullary osteosynthesis).

\begin{tabular}{|c|c|c|c|c|c|c|c|c|c|c|}
\hline $\begin{array}{c}\text { Procedure/ } \\
\text { Severity } \\
\text { (Russel-Taylor) }\end{array}$ & Anaemia & Dead & $\begin{array}{c}\text { Fracture } \\
\text { of } \\
\text { Material } \\
\text { Revision) }\end{array}$ & Wound-Revision & $\begin{array}{c}\text { Malrotation } \\
\text { Femur } \\
\text { renal } \\
\text { failure }\end{array}$ & $\begin{array}{c}\text { Throm-bosis } \\
\text { Implant-Dislocation } \\
\text { (Revision) }\end{array}$ & Sepsis & Implant-Infection & Wound-Infection \\
\hline $\mathrm{EO} / 2 \mathrm{~B}(\mathrm{~N}=13)$ & & & 1 & 1 & & & & 1 & 1 \\
\hline $\begin{array}{c}\mathrm{IO} / 2 \mathrm{~B} \\
(\mathrm{~N}=28)\end{array}$ & 8 & 1 & 1 & 1 & & 2 & & 1 & \\
\hline $\begin{array}{c}\mathrm{IO} / 2 \mathrm{~A} \\
(\mathrm{~N}=1)\end{array}$ & & & & & & & & & 1 \\
\hline $\begin{array}{c}\mathrm{IO} / \mathrm{B} \\
(\mathrm{N}=27)\end{array}$ & 9 & & 1 & & 1 & & 1 & & 1 & \\
\hline
\end{tabular}


(Table 8) contd....

\begin{tabular}{|c|c|c|c|c|c|c|c|c|c|c|c|}
\hline \begin{tabular}{|c|} 
Procedure/ \\
Severity \\
(Russel-Taylor)
\end{tabular} & Anaemia & Dead & \begin{tabular}{|c|}
$\begin{array}{c}\text { Fracture } \\
\text { of } \\
\text { Material } \\
\text { (Revision) }\end{array}$ \\
\end{tabular} & Wound-Revision & $\begin{array}{c}\text { Malrotation } \\
\text { Femur }\end{array}$ & \begin{tabular}{|c|} 
Acute \\
renal \\
failure
\end{tabular} & Throm-bosis & $\begin{array}{c}\text { Implant-Dislocation } \\
\text { (Revision) }\end{array}$ & Sepsis & Implant-Infection & Wound-Infection \\
\hline $\begin{array}{c}\mathrm{IO} / 1 \mathrm{~A} \\
(\mathrm{~N}=8)\end{array}$ & 3 & 1 & & & & & & & & & \\
\hline
\end{tabular}

Table 9. Weight-bearing recommendations according to the surgeon's assessment in the surgery report. The chi-squared test showed no significant difference between the techniques $(p=0.127)$.

\begin{tabular}{|c|c|c|c|}
\hline Technique & Full weight bearing & $\begin{array}{c}\text { Partial } \\
\text { weight bearing }\end{array}$ & $\begin{array}{c}\text { No } \\
\text { weight bearing }\end{array}$ \\
\hline Nail osteosynthesis $(\mathrm{N}=64)$ & $8(15.6 \%)$ & $24(34.4 \%)$ & $32(50.0 \%)$ \\
\hline Plate osteosynthesis $(\mathrm{N}=13)$ & $0(0 \%)$ & $5(38.5 \%)$ & $8(61.5 \%)$ \\
\hline
\end{tabular}

\subsection{Postoperative Weight Bearing}

We defined three groups for postoperative weight bearing. Full weight bearing, no weight bearing for 6 weeks followed by increasing weight in steps ( $20 \mathrm{~kg}$ every 2 weeks) and $20 \mathrm{~kg}$ partial weight bearing for 6 weeks with increasing steps $(+20$ $\mathrm{kg}$ every 2 weeks). With regard to postoperative weight bearing, the percentage of patients capable of early or at least partial weight bearing was higher in the group with intramedullary nailing (Table 9). The statistical analysis did not, however, demonstrate a significant difference between the groups.

\section{DISCUSSION}

The findings of this study show that the surgical technique can have far-reaching consequences for patient outcomes. The objective of surgery is to reconstruct the length and the alignment of the limbs concerned. Surgery should also make early mobilisation possible, particularly when it comes to elderly patients [20]. Our study showed faster postoperative weight bearing with intramedullary than with extramedullary surgery. Intramedullary osteosynthesis techniques provide a high degree of stability, making immediate full weight bearing sometimes possible. This improves patient mobilisation and prevents muscle loss. It also considerably reduces the risk of deep vein thrombosis in the legs [11,8]. In addition, our findings showed a significantly shorter duration of surgery when the intramedullary technique was used, which is particularly important when it comes to elderly patients with a high anaesthetic risk.

Important differences, e.g., increased blood loss, longer duration of surgery, longer duration of radiation exposure and longer hospital stay, were found, including that intramedullary systems were superior to extramedullary systems $[4,20]$. The costs of extramedullary implants are currently lower than those of intramedullary systems. But longer surgical times, however, reduce this economic advantage. If longer hospital stays on account of the extramedullary technique are also taken into account, the advantage of less expensive implants is reduced even more. With regard to the length of hospital stay, our study also found significantly shorter stays for patients with IO, as reported by other authors, too [20]. But interestingly, we found that the length of hospital stay decreases with increasing patient age. However, elderly patients frequently came from care facilities and, in uncomplicated cases, were discharged early and transferred back to such facilities. On the other hand, patients who were discharged home had to be mobile and fit enough to cope with daily life and required more time in the hospital unless they were transferred directly to a rehabilitation facility.

We found that common complications not requiring revision surgery, e.g., anaemia or renal failure, occurred more often in the intramedullary group than in the extramedullary group. The frequency of complications requiring revision surgery, e.g., dislocation or fracture of the implant, was higher in the extramedullary group. Although the complication rate has decreased considerably in recent years due to improvements in techniques and materials used, studies have shown that up to a quarter of patients experience complications [27]. Complication rates are extremely variable due to the wide range of subtrochanteric fractures and the fact that recommendations concerning osteosynthetic procedures are different. Other authors described above all delayed fracture healing, pseudoarthroses, malalignment (medialisation), implant failure, haematoma, infections, and the development of chronic pain and restricted mobility [7,9]. It also indicates an increased occurrence of complications after extramedullary osteosynthesis $[4,28]$. Complication rates in cases of shaft fractures such as implant failure/insufficient reduction and wound infections were $1.48 \%$ for nailing and $3.1 \%$ for plating [4]. By contrast, a meta-analysis conducted by Liu et al. in 2015 found no statistically significant differences in postoperative complications between IO and EO [29]. That study and our study show that elderly patients, in particular, can benefit from the intramedullary technique on account of lower revision surgery rates, reduced implant failure, and fewer fracture healing problems [30]. Treatment decisions will ultimately be influenced by osteoporosis. Due to the retrospective design, it was not possible to ask all involved surgeons why deciding for intra- or extramedullary osteosynthesis, what is a limitation in this study as the fact, that EO was performed only in one of the two study centres. As both techniques, intra- and extramedullary, appear to have their justifications, sufficient and stable bone for fixing each type of implant will be decisive for successful healing.

Retrospective design and the small number of plate osteosynthesis were limitations in this study as well as the unequal distribution of severity of fractures in the groups. All extramedullary procedures were performed in cases where 
fractures were classified as Russel-Taylor $2 \mathrm{~B}(\mathrm{~N}=21)$, while intramedullary fixation was performed in 8 cases of $1 \mathrm{~A}, 27$ cases of $1 \mathrm{~B}$, one case of $2 \mathrm{~A}$ and 20 cases of $2 \mathrm{~B}$. For this reason, separate regression analysis for Russel-Taylor $2 \mathrm{~B}$ fractures was performed to have more reliable results.

\section{CONCLUSION}

In conclusion, intramedullary osteosynthesis offers numerous advantages in the treatment of subtrochanteric femoral fractures. These include shorter duration of surgery, lower revision surgery rates, shorter hospital stays, and earlier mobilisation. Nevertheless, there are indications for extramedullary techniques, particularly when the loss of bone substance must be avoided and open reduction is necessary. The surgeon's experience and patient's age were identified as important factors that influence treatment outcomes. Although implants for IO are more expensive than implants for EO, the duration of surgery and hospital stay as well as the number of revisions, might lead to the conclusion that IO has economic advantages compared to EO. The findings of this study must be evaluated in light of its limitations and are a starting point for prospective studies.

\section{LIST OF ABBREVIATIONS}

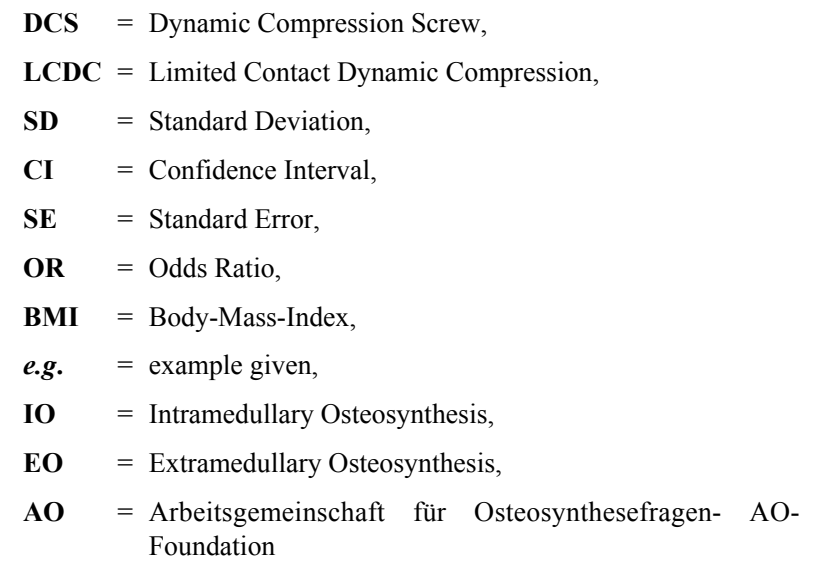

\section{ETHICS APPROVAL AND CONSENT TO PARTI- CIPATE}

The authors confirm that the ethic approval we seeked from the ethic commitee of lower saxony in Hannover in 2015. This commitee allowed to do this investigation without formal approval due to retrospective nature of the study.

\section{HUMAN AND ANIMAL RIGHTS}

Not applicable.

\section{CONSENT FOR PUBLICATION}

All patients in the participating hospitals signed a written consents for the anonym use of data for scientific and statistical evaluation.

\section{AVAILABILITY OF DATA AND MATERIALS}

Not applicable.

\section{FUNDING}

None.

\section{CONFLICT OF INTEREST}

The authors declare no conflict of interest, financial or otherwise.

\section{ACKNOWLEDGEMENTS}

Declared none.

\section{REFERENCES}

[1] Gjertsen JE, Dybvik E, Furnes O, et al. Improved outcome after hip fracture surgery in Norway. Acta Orthop 2017; 88(5): 505-11. [http://dx.doi.org/10.1080/17453674.2017.1344456] [PMID: 28681677]

[2] Haas N, Kretek C. 2012.

[3] Bücking B, Buchholtz S. Trochanteric fractures - surgical treatment and short term outcome Per- und subtrochantäre Femurfrakturen Versorgungsstrategie und Behandlungsergebnisse. Deutscher ÄrzteVerlag OUP 2012; 1(4): 153-9.

[4] Burnei C, Popescu G, Barbu D, Capraru F. Intramedullary osteosynthesis versus plate osteosynthesis in subtrochanteric fractures. J Med Life 2011; 4(4): 324-9. [PMID: 22514563]

[5] Codesido P, Mejía A, Riego J, Ojeda-Thies C. Subtrochanteric fractures in elderly people treated with intramedullary fixation: quality of life and complications following open reduction and cerclage wiring versus closed reduction. Arch Orthop Trauma Surg 2017; 137(8): 1077-85.

[http://dx.doi.org/10.1007/s00402-017-2722-y] [PMID: 28555367]

[6] Kraus M, Krischak G, Wiedmann K, et al. [Clinical evaluation of PFNA ${ }^{\circledR}$ and relationship between the tip-apex distance and mechanical failure]. Unfallchirurg 2011; 114(6): 470-8 [http://dx.doi.org/10.1007/s00113-011-1975-0] [PMID: 21626197]

[7] Stannard. Stuttgart: Spezielle Unfallchirurgie. Georg Thieme Verlag KG 2012; pp. 634-56.

[8] Joglekar SB, Lindvall EM, Martirosian A. Contemporary management of subtrochanteric fractures. Orthop Clin North Am 2015; 46(1): 21-35.

[http://dx.doi.org/10.1016/j.ocl.2014.09.001] [PMID: 25435032]

[9] Hak DJ, Wu H, Dou C, Mauffrey C, Stahel PF. Challenges in Subtrochanteric Femur Fracture Management. Orthopedics 2015; 38(8): 498-502.

[http://dx.doi.org/10.3928/01477447-20150804-06]

[PMID: 26270747

[10] Falkensammer ML, Benninger E, Meier C. Reduction Techniques for Trochantericand Subtrochanteric Fractures of the Femur: a Practical Guide. Acta Chir Orthop Traumatol Cech 2016; 83(5): 300-10. [PMID: 28102804]

[11] Ulmar B, Simon S, Stratos I, Mittlmeier T. [Repositioning, reduction and surgical approaches for subtrochanteric femoral fractures]. Unfallchirurg 2013; 116(12): 1115-22.

[http://dx.doi.org/10.1007/s00113-013-2536-5] [PMID: 24337554]

[12] Tomás J, Teixidor J, Batalla L, Pacha D, Cortina J. Subtrochanteric fractures: treatment with cerclage wire and long intramedullary nail. J Orthop Trauma 2013; 27(7): e157-60.

[http://dx.doi.org/10.1097/BOT.0b013e31826fc03f] [PMID: 22932753]

[13] Haidukewych GJ, Berry DJ. Nonunion of fractures of the subtrochanteric region of the femur. Clin Orthop Relat Res 2004; (419): $185-8$.

[http://dx.doi.org/10.1097/00003086-200402000-00030] [PMID: 15021152]

[14] Loizou CL, McNamara I, Ahmed K, Pryor GA, Parker MJ Classification of subtrochanteric femoral fractures. Injury 2010; 41(7): 739-45.

[http://dx.doi.org/10.1016/j.injury.2010.02.018] [PMID: 20394921]

[15] Seinsheimer F. Subtrochanteric fractures of the femur. J Bone Joint Surg Am 1978; 60(3): 300-6.

[http://dx.doi.org/10.2106/00004623-197860030-00004] [PMID 649632]

[16] Müller ME. [Classification and international AO-documentation of femur fractures]. Unfallheilkunde 1980; 83(5): 251-9. 
[PMID: 7404864]

[17] Browner BD, Jupiter JB, Levine AM. Skeletal Trauma: Fractures, Dislocations, Ligamentous Injuries. Philadelphia: Saunders 1992.

[18] Ansari Moein CMS, Gerrits PD, ten Duis HJ. Trochanteric fossa or piriform fossa of the femur: time for standardised terminology? Injury 2013; 44(6): 722-5.

[http://dx.doi.org/10.1016/j.injury.2012.08.049] [PMID: 23026115]

[19] Guyver PM, McCarthy MJ, Jain NP, Poulter RJ, McAllen CJ, Keenan J. Is there any purpose in classifying subtrochanteric fractures? The reproducibility of four classification systems. Eur J Orthop Surg Traumatol 2014; 24(4): 513-8.

[http://dx.doi.org/10.1007/s00590-011-0780-3] [PMID: 23412146]

[20] Yadav S, Sinha S, Luther E, Arora NC, Prasad M, Varma R. Comparison of extramedullary and intramedullary devices for treatment of subtrochanteric femoral fractures at tertiary level center. Chin J Traumatol 2014; 17(3): 141-5.

[PMID: 24889976]

[21] Büttner O, Styger S, Regazzoni P, Suhm N. [Stabilization of inter- and subtrochanteric femoral fractures with the PFNA $\left.{ }^{\circledR}\right]$. Oper Orthop Traumatol 2011; 23(5): 357-74.

[PMID: 22037622]

[22] Kuzyk PR, Bhandari M, McKee MD, Russell TA, Schemitsch EH. Intramedullary versus extramedullary fixation for subtrochanteric femur fractures. J Orthop Trauma 2009; 23(6): 465-70. [http://dx.doi.org/10.1097/BOT.0b013e3181acfdfd]

[PMID: 19550236]

[23] Wirtz C, Abbassi F, Evangelopoulos DS, Kohl S, Siebenrock KA, Krüger A. High failure rate of trochanteric fracture osteosynthesis with proximal femoral locking compression plate. Injury 2013; 44(6): 751-6.

[http://dx.doi.org/10.1016/j.injury.2013.02.020] [PMID: 23522837]
[24] Saini P, Kumar R, Shekhawat V, Joshi N, Bansal M, Kumar S. Biological fixation of comminuted subtrochanteric fractures with proximal femur locking compression plate. Injury 2013; 44(2): 226-31. [http://dx.doi.org/10.1016/j.injury.2012.10.037] [PMID: 23200761]

[25] El-Desouky II, Mohamed MM, Kandil AE. Clinical outcome of conventional versus biological fixation of subtrochanteric fractures by proximal femoral locked plate. Injury 2016; 47(6): 1309-17. [http://dx.doi.org/10.1016/j.injury.2016.03.016] [PMID: 27015752]

[26] Dumbre Patil SS, Karkamkar SS, Patil VS, Patil SS, Ranaware AS Reverse distal femoral locking compression plate a salvage option in nonunion of proximal femoral fractures. Indian J Orthop 2016; 50(4): 374-8.

[http://dx.doi.org/10.4103/0019-5413.185598] [PMID: 27512218]

[27] Sehmisch S, Rieckenberg J, Dresing K. [Stabilization of unstable intertrochanteric fractures with the proximal femoral nail]. Oper Orthop Traumatol 2013; 25(1): 63-83.

[http://dx.doi.org/10.1007/s00064-012-0226-z] [PMID: 23381739]

[28] Matre K, Havelin LI, Gjertsen JE, Vinje T, Espehaug B, Fevang JM. Sliding hip screw versus IM nail in reverse oblique trochanteric and subtrochanteric fractures. A study of 2716 patients in the Norwegian Hip Fracture Register. Injury 2013; 44(6): 735-42. [http://dx.doi.org/10.1016/j.injury.2012.12.010] [PMID: 23305689]

[29] Liu $\mathrm{P}, \mathrm{Wu} \mathrm{X}$, Shi $\mathrm{H}$, et al. Intramedullary versus extramedullary fixation in the management of subtrochanteric femur fractures: a metaanalysis. Clin Interv Aging 2015; 10: 803-11.

[PMID: 25960644]

[30] Das S, Forrest K, Howell S. General anaesthesia in elderly patients with cardiovascular disorders: choice of anaesthetic agent. Drugs Aging 2010; 27(4): 265-82.

[http://dx.doi.org/10.2165/11534990-000000000-00000] [PMID: 20359259]

\section{(C) 2020 Schulze et al.}

This is an open access article distributed under the terms of the Creative Commons Attribution 4.0 International Public License (CC-BY 4.0), a copy of which is available at: https://creativecommons.org/licenses/by/4.0/legalcode. This license permits unrestricted use, distribution, and reproduction in any medium, provided the original author and source are credited. 